\title{
Behaviour change techniques targeting both diet and physical activity in type 2 diabetes: A systematic review and meta-analysis
}

\author{
Kevin A. Cradock ${ }^{1,2}$, Gearóid ÓLaighinn ${ }^{2,3}$, Francis M. Finucane ${ }^{4}$, Heather L. Gainforth ${ }^{5}$, Leo R. Quinlan ${ }^{\text {* }}$
} and Kathleen A. Martin Ginis ${ }^{6}$

\begin{abstract}
Background: Changing diet and physical activity behaviour is one of the cornerstones of type 2 diabetes treatment, but changing behaviour is challenging. The objective of this study was to identify behaviour change techniques (BCTs) and intervention features of dietary and physical activity interventions for patients with type 2 diabetes that are associated with changes in $\mathrm{HbA}_{1 \mathrm{c}}$ and body weight.

Methods: We performed a systematic review of papers published between 1975-2015 describing randomised controlled trials (RCTs) that focused exclusively on both diet and physical activity. The constituent BCTs, intervention features and methodological rigour of these interventions were evaluated. Changes in $\mathrm{HbA}_{1 c}$ and body weight were meta-analysed and examined in relation to use of BCTs.

Results: Thirteen RCTs were identified. Meta-analyses revealed reductions in $\mathrm{HbA}_{1 \mathrm{c}}$ at 3, 6, 12 and 24 months of -1. $11 \%(12 \mathrm{mmol} / \mathrm{mol}),-0.67 \%(7 \mathrm{mmol} / \mathrm{mol}),-0.28 \%(3 \mathrm{mmol} / \mathrm{mol})$ and $-0.26 \%(2 \mathrm{mmol} / \mathrm{mol})$ with an overall reduction of $-0.53 \%(6 \mathrm{mmol} / \mathrm{mol}[95 \% \mathrm{Cl}-0.74$ to $-0.32, P<0.00001])$ in intervention groups compared to control groups. Meta-analyses also showed a reduction in body weight of $-2.7 \mathrm{~kg},-3.64 \mathrm{~kg},-3.77 \mathrm{~kg}$ and $-3.18 \mathrm{~kg}$ at $3,6,12$ and 24 months, overall reduction was $-3.73 \mathrm{~kg}(95 \% \mathrm{Cl}-6.09$ to $-1.37 \mathrm{~kg}, P=0.002)$.

Four of $46 \mathrm{BCTs}$ identified were associated with $>0.3 \%$ reduction in $\mathrm{HbA}_{1 \mathrm{c}}$ : 'instruction on how to perform a behaviour', 'behavioural practice/rehearsal', 'demonstration of the behaviour' and 'action planning', as were intervention features 'supervised physical activity', 'group sessions', 'contact with an exercise physiologist', 'contact with an exercise physiologist and a dietitian', 'baseline $\mathrm{HbA}_{1 \mathrm{c}}>8 \%$ ' and interventions of greater frequency and intensity.
\end{abstract}

Conclusions: Diet and physical activity interventions achieved clinically significant reductions in $\mathrm{HbA}_{1 c}$ at three and six months, but not at 12 and 24 months. Specific BCTs and intervention features identified may inform more effective structured lifestyle intervention treatment strategies for type 2 diabetes.

Keywords: Behaviour change techniques, Diet, Physical activity, Type 2 diabetes, HbA ${ }_{1 c}$ Systematic review, Meta-analysis

\footnotetext{
* Correspondence: leo.quinlan@nuigalway.ie

'Physiology, School of Medicine, NUI Galway, University Road, Galway,

Ireland

Full list of author information is available at the end of the article
} 


\section{Background}

Type 2 diabetes is one of the fastest growing and largest global health burdens. In 2015, there were 415 million people with diabetes worldwide (91 \% of which were type 2 diabetes) with figures expected to rise to 642 million by the year 2040, [1] which easily surpasses earlier predictions of 366 million by 2030 [2]. A 2010 global analysis of mortality reported that 1.3 million deaths worldwide were due to diabetes that year, twice as many as in 1990 [3].

Type 2 diabetes is diagnosed based on a fasting plasma glucose (FPG $\geq 126 \mathrm{mg} / \mathrm{dL}$ [7 mmol/L]) or the two hour plasma glucose value following a $75 \mathrm{~g}$ oral glucose tolerance test $(>200 \mathrm{mg} / \mathrm{DL}[11.0 \mathrm{mmol} / \mathrm{L}])$ or having a $\mathrm{HbA}_{1 \mathrm{c}}$ of $\geq 6.5 \%$ according to the American Diabetes Association (ADA) [4]. Glycosylated haemoglobin $\mathrm{A}_{1 \mathrm{c}}$ $\left(\mathrm{HbA}_{1 \mathrm{c}}\right.$ haemoglobin to which glucose is bound, is tested to determine average blood glucose level over the past two to three months) [1] is widely regarded as an accurate measurement for diabetes assessment and the ADA recommend that $\mathrm{HbA}_{1 \mathrm{c}}$ testing be performed on all patients with diabetes at initial diagnosis and as part of continuing treatment [4]. $\mathrm{HbA}_{1 \mathrm{c}}$ reduction of $0.5 \%$ (6 $\mathrm{mmol} / \mathrm{mol}$ ) is regarded as clinically significant [5], while other authors suggest $0.3 \%(4 \mathrm{mmol} / \mathrm{mol})[6,7]$ or $0.33 \%(4 \mathrm{mmol} / \mathrm{mol})$ [8]. $\mathrm{HbA}_{1 \mathrm{c}}$ was selected as the primary outcome for this review as it represents the most widely used measure of type 2 diabetes control and treatment efficacy.

Type 2 diabetes is a mulifactorial lifestyle disease, linked to dietary habits and sedentary behaviour [9]. The ADA included 'support patient behavioural change' as one of their three key objectives for improving diabetes care and stated that 'lifestyle changes of increasing physical activity, eating a healthy diet, cessation of smoking, weight loss and coping strategies' was one of their key diabetes treatment foci [4]. Importantly, all three ADA treatment foci revolve around changing patients' behaviour.

RCTs and epidemiological data have shown that type 2 diabetes can be prevented. However, changing diet and lifestyle behaviour requires change at an individual, environmental, social, and policy level [10]. Previous authors have identified as key research recommendations the need to investigate the effects of multiple behaviour changes in people who have been diagnosed with type 2 diabetes [11] and multiple BCT use associated with clinically significant changes in $\mathrm{HbA}_{1 \mathrm{c}}$ [7].

Precise specification of the active ingredients (BCTs) and intervention features of diet and physical activity interventions in type 2 diabetes will help build cumulative evidence towards delivering effective replicable interventions. Behaviour change technqiues (BCTs) have been identified in previous similar studies of diet and/or physical activity in type 2 diabetes [7, 12] and other subjects [13-16]. Previously identified BCTs associated with success in changing diet and/or physical activity behaviour include: 'instruction on how to perform a behaviour,' 'behavioural practice/rehearsal', 'demonstration of the behaviour', 'action planning, 'problem solving', 'feedback on behaviour,' 'self-monitoring of behaviour,' 'goal setting,' 'goal review', 'social support,' 'prompt practice,' 'use of follow up prompts', and 'prompting generalisation of a target behaviour' [7, 12-15, 17, 18].

However, to our knowledge, there has been no systematic review and meta-analysis identifying the behaviour change techniques (BCTs) associated with greatest improvements in $\mathrm{HbA}_{1 \mathrm{c}}$ in interventions combining diet and physical activity in type 2 diabetes treatment. We sought to identify which BCTs exclusively change only the behaviours of diet and physical activity. Interventions containing multiple behaviours or additional behaviours were not included in this review. Behaviour change has contributed to the morbidity and mortality associated with type 2 diabetes [19] but might also contribute to the solution [20]. However the effectiveness of behaviour change interventions varies considerably and their mechanisms are not fully understood [20]. The overall effects of diet and physical activity behavioural interventions in maintaining weight loss are moderate and future research on increasing effectiveness of interventions is required [21].

The primary objective of this study was to identify BCTs and intervention features which reduced $\mathrm{HbA}_{1 \mathrm{c}}$. A secondary objective was to identify the frequency of use of BCTs in included studies. A third objective was to describe changes in $\mathrm{HbA}_{1 \mathrm{c}}$ and weight at different time points.

\section{Methods}

A PRISMA (Preferred Reporting Items for Systematic Reviews and Meta-Analyses) checklist was created and PRISMA review guidelines were followed [22] (Additional file 1: 1.1).

\section{Inclusion criteria}

(i) Randomised controlled trials (RCTs) of any duration with a dietary AND physical activity intervention, published in peer-reviewed journals between 1/1/ 1975 and $1 / 6 / 2015$.

(ii) RCTs with a comparison arm or control group that constituted usual care.

(iii) Human participants older than 18 years of age with clinically confirmed type 2 diabetes, at time of recruitment.

(iv) Primary clinical outcome measure was $\mathrm{HbA}_{1 \mathrm{c}}$, however studies reporting $\mathrm{HbA}_{1 \mathrm{c}}$ results as an outcome measure were also included. Body weight 
was reported as a secondary outcome (because of the inconsistency and variety of measures of dietary and physical activity behaviour used in the RCTs, it was not possible to compare behavioural outcomes across trials. Thus, $\mathrm{HbA}_{1 \mathrm{c}}$ was selected as the primary endpoint).

\section{Exclusion criteria}

(i) RCTs of diabetes prevention OR RCTs of those at risk of type 2 diabetes.

(ii) RCTs that used pharmacological agents exclusively to treat type 2 diabetes.

(iii) RCTs that targeted multiple chronic diseases, gestational diabetes or type 1 diabetes.

(iv) RCTs that used additional interventions beyond diet and physical activity, or focused on additional behaviours other than diet and physical activity.

(v) Studies not reported in English.

(vi) Studies not reporting $\mathrm{HbA}_{1 \mathrm{c}}$ as an outcome measure.

\section{Information sources and search strategy}

Cochrane Library, CINAHL, EMBASE, PubMed, PsycINFO, and SCOPUS databases were systematically searched using a Boolean combination of key words and $\mathrm{MeSH}$ headings (Additional file 1: 1.2). Additional records identified through other sources such as reference lists of relevant reviews and included studies were searched for additional studies. The original search was conducted in April 2014 and repeated June 2015. Reference lists of included articles were also checked for relevant articles.

\section{Article screening}

Articles were initially screened by two research team members based on titles and abstracts and then full texts of the remaining articles (KC and KMG). The final set of included articles was agreed on by the entire team (see Fig. 1 for search process). Inter-rater agreement by Cohen's Kappa for the full text search results was 0.86 .

\section{Data extraction process}

Data were extracted using standardised data extraction templates and compiled in an Excel file. All data extraction was carried out independently by at least two members of the team ( $\mathrm{KC}$ and $\mathrm{KMG}$ ). If additional study information was required, corresponding authors were contacted by email using a standardised template, papers reporting on the same trial were sought (e.g. Methods papers), and when available, supplementary online information was accessed.

\section{Risk of bias and fidelity assessment}

Risk of bias in individual studies was assessed using the Cochrane Collaboration risk of bias tool, [23] whereby criteria are applied to seven aspects of trials to yield an appraisal of 'low risk', 'high risk' or 'unclear risk' of bias. RCTs were independently assessed by two members of the review team for methodological quality and risk of bias (KC and KMG). Treatment fidelity was assessed using Bellg et al.'s [24] criteria, which identify treatment fidelity strategies for improving and monitoring, provider training, delivery of treatment, receipt of treatment, and enactment of treatment skills. Each category contains subcategories which were each assigned a score of yes, no, or unclear. However, fidelity measures using this dichotomous type response don't capture the degree of use of fidelity, therefore a continuum type scoring or rating of parameters may provide a more accurate assessment of fidelity.

\section{Coding of behaviour change techniques}

Michie's v1 BCT taxonomy [25] was used to identify and code the BCTs reported in each study. This rigorously developed and validated taxonomy consists of clear definitions of 93 different BCTs, divided into 16 different categories. The taxonomy was developed to facilitate consistent classification and reporting of the use of BCTs by researchers and clinicians. Since its publication, it has become the standard for classifying and reporting BCTs in the health behaviour change literature. BCTs were coded separately for physical activity behaviour and for diet behaviour; a BCT was only coded when it was explicitly mentioned in the intervention methodology. (All studies coded and associated text are documented in Additional file 2). BCTs were coded separately for intervention and control groups. BCTs for diet only and physical activity only were combined in an excel spreadsheet, if a BCT was present in diet only or physical activity only or in both diet and physical activity it is reported as present for combined diet and physical activity (see Table 1). A coding rubric/ rulebook was developed by three authors of this review (KC, LQ and HG) to guide the coding process (Additional file 1: 1.3). All included studies were coded independently by two authors (KC and LQ) who underwent training in the use of Michie's taxonomy [26]. A third master coder (HG) independently assessed the coding results and had final say in the event of disagreements. Cohen's kappa and PABAK calculations were used to establish inter-coder reliability of BCTs present and absent. A BCT had to be used in at least three studies to be included in the moderator analysis.

\section{Coding of intervention features}

Rationale for features included was derived from intervention features identified previously [27], previous reviews 


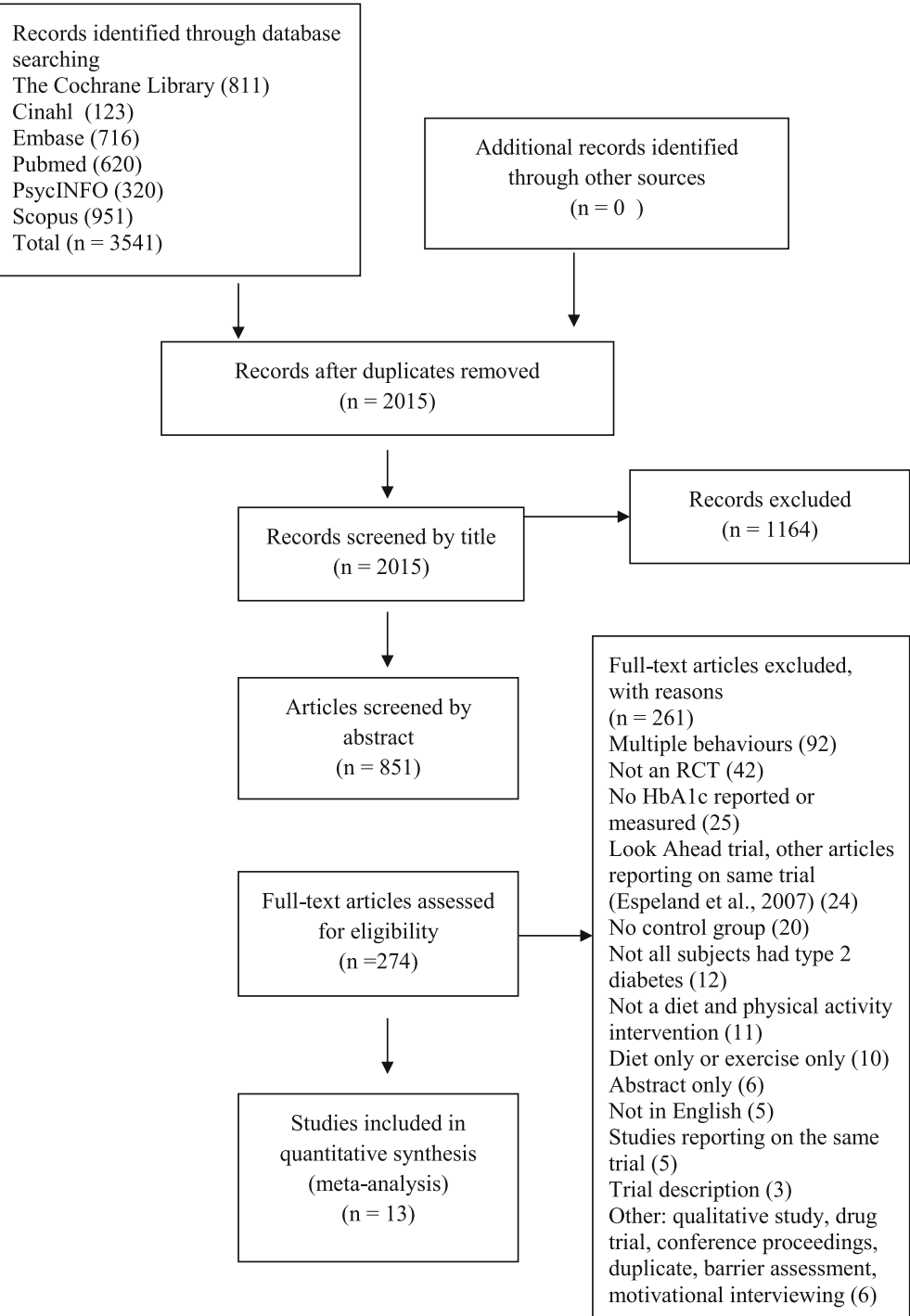

Fig. 1 PRISMA 2009 Flow diagram of search strategy

$[7,17]$ and the 'Theory Coding Scheme' [28] which guided theory coding of intervention content. Intervention features were included under the headings "mode of delivery", "frequency", "provider", "intensity" and "other" (use of theory and baseline $\mathrm{HbA}_{1 \mathrm{c}}$, number of BCTs included). Intensity for total number of contacts and total number of face-to-face contacts with intervention personnel used the mean and median to categorise variables into high (above mean/median) and low intensity (below mean/median). Frequency of 'total' and 'face -to-face' contacts also used above and below the mean/median to categorise the average number of weeks between contacts as high frequency (below) and low frequency (above). All other intervention features were analysed dichotomously using yes/no to indicate presence or absence. Rationale for categorising baseline $\mathrm{HbA}_{1 \mathrm{c}}$ levels comes from a large epidemiology study which identified that $\mathrm{HbA}_{1 \mathrm{c}}$ levels $\geq 7 \%$ were associated with increased risk of death [29]. We also ran the moderator analysis using above and below $8 \%(64 \mathrm{mmol} /$ mol) to categorise high and low $\mathrm{HbA}_{1 \mathrm{c}}$ as standard diabetes control targets aim to keep $\mathrm{HbA}_{1 \mathrm{c}}$ between 7.0 and $7.9 \%$ [29] therefore $\mathrm{HbA}_{1 \mathrm{c}}$ levels $>8 \%$ represent poorly controlled type 2 diabetes.

\section{Analysis}

$\mathrm{HbA}_{1 \mathrm{c}}$ reductions of $\geq 0.3 \%$ were deemed clinically significant, which follows the precedent set by other authors $[6,7]$. Meta-analyses were conducted using RevMan (v5.3) on the primary outcome measure of $\mathrm{HbA}_{1 \mathrm{c}}$ and the secondary outcome of body weight. Changes were calculated as the difference in $\mathrm{HbA}_{1 \mathrm{c}}$ from baseline to a particular time-point $\left(3,6,12\right.$, and 24 months), and reductions in $\mathrm{HbA}_{1 \mathrm{c}}$ were 
Table 1 BCTs used in dietary AND physical activity aspect of intervention

\begin{tabular}{|c|c|c|c|c|c|c|c|c|c|c|c|c|c|c|c|}
\hline BCT no. & BCT Label & (1) & (2) & (3) & (4) & (5) & (6) & (7) & (8) & (9) & (10) & (11) & $(12)$ & (13) & Total \\
\hline 4.1 & Instruction on how to perform a behaviour & $\checkmark$ & $\checkmark$ & $\checkmark$ & $\checkmark$ & $\checkmark$ & $\checkmark$ & $\checkmark$ & $\checkmark$ & $\checkmark$ & $\checkmark$ & $\checkmark$ & $\checkmark$ & $\checkmark$ & 13 \\
\hline 1.4 & Action planning & $\checkmark$ & $\checkmark$ & $\checkmark$ & $\checkmark$ & $\checkmark$ & $\checkmark$ & $\checkmark$ & $\checkmark$ & $\checkmark$ & $\checkmark$ & $\checkmark$ & $\checkmark$ & & 12 \\
\hline 9.1 & Credible source & $\checkmark$ & $\checkmark$ & $\checkmark$ & $\checkmark$ & $\checkmark$ & $\checkmark$ & $\checkmark$ & $\checkmark$ & & $\checkmark$ & $\checkmark$ & $\checkmark$ & $\checkmark$ & 12 \\
\hline 1.1 & Goal setting (behaviour) & $\checkmark$ & $\checkmark$ & $\checkmark$ & $\checkmark$ & $\checkmark$ & $\checkmark$ & & $\checkmark$ & $\checkmark$ & $\checkmark$ & $\checkmark$ & $\checkmark$ & & 11 \\
\hline 1.3 & Goal setting (outcome) & $\checkmark$ & $\checkmark$ & $\checkmark$ & $\checkmark$ & & $\checkmark$ & $\checkmark$ & & & $\checkmark$ & $\checkmark$ & $\checkmark$ & $\checkmark$ & 10 \\
\hline 3.1 & Social support (unspecified) & $\checkmark$ & $\checkmark$ & $\checkmark$ & $\checkmark$ & $\checkmark$ & & & & $\checkmark$ & $\checkmark$ & $\checkmark$ & $\checkmark$ & $\checkmark$ & 10 \\
\hline 2.3 & Self-monitoring of behaviour & $\checkmark$ & $\checkmark$ & $\checkmark$ & $\checkmark$ & $\checkmark$ & $\checkmark$ & $\checkmark$ & $\checkmark$ & & $\checkmark$ & & & & 9 \\
\hline 2.2 & Feedback on behaviour & $\checkmark$ & & $\checkmark$ & $\checkmark$ & & & $\checkmark$ & $\checkmark$ & $\checkmark$ & & $\checkmark$ & & & 7 \\
\hline 6.1 & Demonstration of the behaviour & $\checkmark$ & & $\checkmark$ & $\checkmark$ & $\checkmark$ & & $\checkmark$ & & $\checkmark$ & & $\checkmark$ & & & 7 \\
\hline 8.7 & Graded tasks & $\checkmark$ & $\checkmark$ & $\checkmark$ & $\checkmark$ & $\checkmark$ & $\checkmark$ & $\checkmark$ & & & & & & & 7 \\
\hline 12.5 & Adding objects to the environment & & $\checkmark$ & $\checkmark$ & $\checkmark$ & $\checkmark$ & & $\checkmark$ & $\checkmark$ & $\checkmark$ & & & & & 7 \\
\hline 1.2 & Problem solving & $\checkmark$ & & $\checkmark$ & $\checkmark$ & $\checkmark$ & & & & & $\checkmark$ & & & & 5 \\
\hline 2.5 & Monitoring outcome(s) of behaviour by others without feedback & $\checkmark$ & $\checkmark$ & & $\checkmark$ & & & & $\checkmark$ & & & & & $\checkmark$ & 5 \\
\hline 8.1 & Behavioural practice/rehearsal & $\checkmark$ & & & $\checkmark$ & $\checkmark$ & & $\checkmark$ & & & & $\checkmark$ & & & 5 \\
\hline 12.3 & Avoidance/reducing exposure to cues for the behaviour & $\checkmark$ & & $\checkmark$ & $\checkmark$ & $\checkmark$ & & & & & & & & & 4 \\
\hline 1.5 & Review behaviour goal(s) & & & & $\checkmark$ & & & $\checkmark$ & & & & $\checkmark$ & & & 3 \\
\hline 1.7 & Review outcome goal(s) & & $\checkmark$ & & $\checkmark$ & & & & & $\checkmark$ & & & & & 3 \\
\hline 2.4 & Self-monitoring of outcome(s) of behaviour & & $\checkmark$ & $\checkmark$ & $\checkmark$ & & & & & & & & & & 3 \\
\hline 2.7 & Feedback on outcome(s) of behaviour & & & $\checkmark$ & $\checkmark$ & & & & & $\checkmark$ & & & & & 3 \\
\hline 12.1 & Restructuring the physical environment & & & $\checkmark$ & $\checkmark$ & $\checkmark$ & & & & & & & & & 3 \\
\hline 2.1 & Monitoring of behaviour by others without feedback & & & & & & & & $\checkmark$ & & & & $\checkmark$ & & 2 \\
\hline 3.3 & Social support (emotional) & & & $\checkmark$ & & $\checkmark$ & & & & & & & & & 2 \\
\hline 5.1 & Information about health consequences & & & & $\checkmark$ & $\checkmark$ & & & & & & & & & 2 \\
\hline 6.2 & Social comparison & & & & $\checkmark$ & $\checkmark$ & & & & & & & & & 2 \\
\hline 7.1 & Prompts/cues & & & $\checkmark$ & $\checkmark$ & & & & & & & & & & 2 \\
\hline 8.2 & Behaviour substitution & & & & $\checkmark$ & & & & & & $\checkmark$ & & & & 2 \\
\hline 8.6 & Generalization of a target behaviour & & & $\checkmark$ & & & & & & & & $\checkmark$ & & & 2 \\
\hline 10.3 & Non-specific reward & & & $\checkmark$ & $\checkmark$ & & & & & & & & & & 2 \\
\hline 10.9 & Self-reward & & & $\checkmark$ & $\checkmark$ & & & & & & & & & & 2 \\
\hline 15.4 & Self-talk & & & $\checkmark$ & $\checkmark$ & & & & & & & & & & 2 \\
\hline 1.6 & Discrepancy between current behaviour and goal & & & $\checkmark$ & & & & & & & & & & & 1 \\
\hline
\end{tabular}


Table 1 BCTs used in dietary AND physical activity aspect of intervention (Continued)

\begin{tabular}{|c|c|c|c|}
\hline 2.6 & Biofeedback & $\checkmark$ & 1 \\
\hline 3.2 & Social support (practical) & $\checkmark$ & 1 \\
\hline 7.5 & Remove aversive stimulus & $\checkmark$ & 1 \\
\hline 8.3 & Habit formation & $\checkmark$ & 1 \\
\hline 9.2 & Pros and cons & $\checkmark$ & 1 \\
\hline 10.2 & Material reward (behaviour) & $\checkmark$ & 1 \\
\hline 10.4 & Social reward & $\checkmark$ & 1 \\
\hline 10.6 & Non-specific incentive & $\checkmark$ & 1 \\
\hline 10.7 & Self-incentive & $\checkmark$ & 1 \\
\hline 11.2 & Reduce negative emotions & $\checkmark$ & 1 \\
\hline 12.2 & Restructuring the social environment & $\checkmark$ & 1 \\
\hline 13.1 & Identification of self as role model & $\checkmark$ & 1 \\
\hline 13.2 & Framing/reframing & $\checkmark$ & 1 \\
\hline 15.1 & Verbal persuasion about capability & $\checkmark$ & 1 \\
\hline 15.3 & Focus on past success & $\checkmark$ & 1 \\
\hline
\end{tabular}

Studies are listed in alphabetical order. (1) [43], (2) [45], (3) [46], (4) [38], (5) [37], (6) [41], (7) [72], (8) [44], (9) [40], (10) ([39], (11) [42], (12) [36], (13) [47] 
calculated as the difference between intervention and control groups. Means and standard deviations (SDs) from included studies were converted to mean differences and SDs of the differences between intervention and control groups at 3, 6, 12 and 24 months.

\section{Meta-analysis}

Missing SDs were calculated from $\mathrm{SE}, \mathrm{t}$ and $p$ values, using the Cochrane guidelines [30]. The mean for one study was estimated from the median and range using Hozo's formula [31]. The SD of the difference in means from baseline to the different time points was calculated using the Cochrane guidelines when standard error or $95 \%$ confidence intervals were reported. A strategy documented by previous researchers, which requires a correlation between baseline and end of intervention measurements, was used for the remaining missing data [32, 33]. A correlation of 0.75 was used to calculate the missing SDs for $\mathrm{HbA}_{1 \mathrm{c}}$ data; this value was chosen following a sensitivity analysis using correlations of 0.5 , 0.75 and 0.95 , and a previous review and meta-analysis [34]. A correlation of 0.95 was used to calculate the missing SDs for weight loss data, following a further sensitivity analysis and previous studies [33, 35]. We also calculated the SDs of the difference between baseline and reported time-point means for three studies that reported sufficient data to calculate, and this was consistent with the correlations we used. As this correlation is only an estimate as the raw data was unavailable, it is also suggested that future researchers use the Bayesian principle of combining raw data from similar previously published studies to, calculate missing SDs where available and combine these results on similar subjects to improve the accuracy of this estimation. It was estimated that the $\mathrm{HbA}_{1 \mathrm{c}}$ and weight loss variance is the same at baseline and reported time points for the control and the intervention groups when variance was not reported. Effect heterogeneity was assessed using the $\mathrm{I}^{2}$ method using the Cochrane guidelines [30]. For the overall meta-analysis, data reported at the time point closest to the end of the intervention was used (cf., Avery et al. [7]). A random effects analysis model using the inverse variance statistical method was used. A repeated measures design was not possible as the raw data were unavailable. Statistical significance of the moderator and meta-analysis was set at $p \leq 0.05$.

\section{Moderator analysis}

A moderator analysis was conducted to identify associations between $\mathrm{BCTs}$, intervention features and changes in $\mathrm{HbA}_{1 \mathrm{c}}$ using Comprehensive Meta-Analysis (V3). All studies were combined using data reported at the time point closest to the end of the intervention. The BCTs used for both diet and physical activity aspects of interventions were combined for one meta-analysis where BCTs were included if present in diet only or physical activity only or in both. The moderator analysis used the effect size 'difference in means' to assess the data, and carried out subgroup analysis of the included studies, comparing presence or absence of BCTs or intervention features. A separate moderator analyses were also conducted for dietary BCTs and for physical activity BCTs. BCTs present in the control group were not included in the moderator analysis. A random effects model was used to analyse the data.

\section{Results}

\section{Study selection and study characteristics}

Thirteen studies met the inclusion/exclusion criteria. Summary characteristics of included studies are outlined in Additional file 1: 1.4. One study [36] reported data for males and females separately so these data are presented as a mean of both groups. Average age of participants was $56.7( \pm 3.9)$ years for intervention groups and 56.8 $( \pm 3.9)$ years for controls. For intervention and control groups respectively, mean duration of diabetes, where reported, was $6.9( \pm 1.2)$ and 8 years $( \pm 3)$, mean baseline $\mathrm{HbA}_{1 \mathrm{c}} 8.03 \%( \pm 1.21 \%)$ and $8 \%( \pm 0.95 \%)$, weight $88.5 \mathrm{~kg}( \pm 14.5 \mathrm{~kg})$ and $87.9 \mathrm{~kg}( \pm 14.8 \mathrm{~kg})$. Only one of the included studies [37] was carried out in a community centre setting, all remaining studies were carried out in a clinical setting. All participants included in the thirteen studies were classified as having type 2 diabetes.

\section{Risk of bias and treatment fidelity}

Only one RCT was judged as low risk of bias in each of the seven areas assessed [38]. Nine RCTs were judged to have a combination of low and unclear risk of bias apart from three RCTs which were judged to have a high risk of bias in the 'other bias' category, [37, 39] 'blinding of participants and personnel' and 'blinding of outcome assessment' categories [40] (Additional file 1: 1.5, 1.6). Inter-rater agreement (0.86) was determined by Cohen's kappa for risk of bias assessment. Results of the assessment of treatment fidelity are presented in Additional file 1: 1.7. Overall reported use of treatment fidelity strategies was very low across all categories apart from 'monitoring and improving enactment of treatment skills' where 11 out of 13 studies scored 'yes' in the subcategory 'ensuring participants' use of behavioural skills'. Coding of all subcategories is more comprehensive, however, fidelity assessment is much lower using this method.

\section{Meta-analysis of changes in $\mathrm{HbA}_{1 \mathrm{c}}$ and body weight}

Meta-analyses showed differences in $\mathrm{HbA}_{1 \mathrm{c}}$ between intervention and control groups of $-1.11 \%(12 \mathrm{mmol} / \mathrm{mol}[95 \%$ CI -1.57 to $-0.66, P<0.00001]),-0.67 \%(7 \mathrm{mmol} / \mathrm{mol}[95 \%$ 
CI -1.09 to $-0.24 P=0.002]),-0.28 \%(3 \mathrm{mmol} / \mathrm{mol}[95 \% \mathrm{CI}$ -0.52 to $-0.03, P=0.03])$, and $-0.26 \%(2 \mathrm{mmol} / \mathrm{mol}[95 \%$ CI -0.39 to $-0.14, P<0.001])$, at $3(n=4), 6(n=6), 12(n=$ $5)$ and $24(n=2)$ months respectively (Fig. 2). When all studies and all time points were included in an overall meta-analysis, reduction in $\mathrm{HbA}_{1 \mathrm{c}}$ was $0.53 \%(6 \mathrm{mmol} /$ mol [95 \% CI -0.74 to $-0.32, P<0.00001]$ ) (Fig. 3). Sensitivity analysis showed the magnitude of reduction did not change whether data from time point closest to end of intervention or final time point reported was used in analysis. Heterogeneity as measured by $\mathrm{I}^{2}$ was $41 \%$, $88 \%, 84 \%$ and $25 \%$ at 3, 6, 12 and 24 months respectively.

The difference in body weight between intervention and control groups was $-2.7 \mathrm{~kg}(-4.14-1.26, P=0.06)$, $-3.64 \mathrm{~kg}(-6.05$ to $-1.23, P=0.003),-3.77 \mathrm{~kg}(-7.77$ to $0.22, P=0.06)$, and $-3.18 \mathrm{~kg}(-7.67$ to $1.32, P=0.17)$, at 3 , 6, 12 and 24 months respectively (Additional file 1: 1.8). Overall meta-analysis for body mass showed a reduction of $-3.73 \mathrm{~kg}(-6.09$ to $-1.37, P=0.002)$, (Additional file 1:
1.9). Heterogeneity as measured by $\mathrm{I}^{2}$ was $60 \%$, $91 \%$, $97 \%$ and $98 \%$ at 3, 6, 12 and 24 months respectively.

\section{Diet and physical activity content of interventions}

The majority of included studies focused on a reduction of calories (10 of 13), three studies did not specify the caloric goal of their intervention [37, 41, 42]. There was an additional focus on low fat $[39,43]$, low carbohydrate $[40,44]$ and low glycaemic index [45] in some of the included studies. All of the included studies $(n=13)$ focused on aerobic exercise of a moderate intensity, three also focused on strength training [38, 42, 46] (Additional file 1: 1.10).

\section{BCTs used}

Inter-rater agreement determined by Cohen's kappa was 0.79 and PABAK was 0.92 (Additional file 1: 1.11). A total of 46 different BCTs were applied in the intervention groups. Sixteen of these 46 BCTs were reported only once. The number of BCTs used in a single RCT ranged from 5 [47] to 42 [38], with a mean of 13.5

a Difference in $\mathrm{HbA}_{1 \mathrm{c}}$ at 3 months

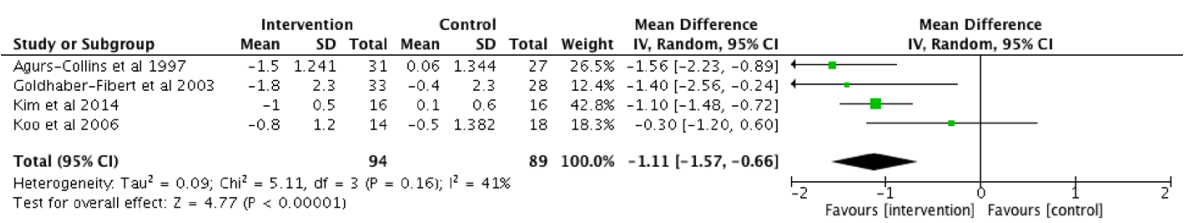

b Difference in $\mathrm{HbA}_{1 \mathrm{c}}$ at 6 months

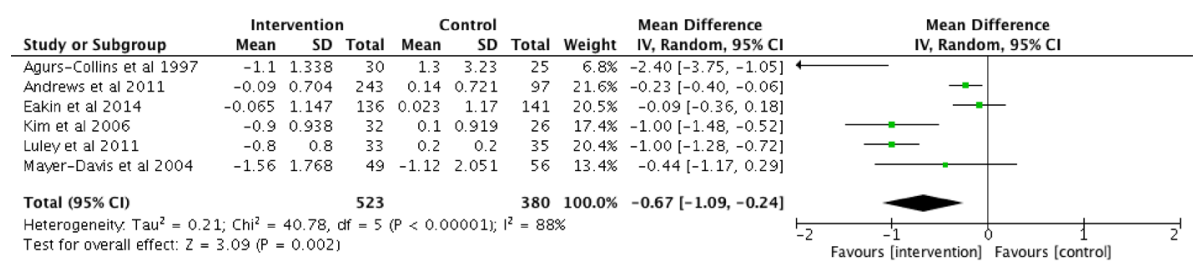

Difference in $\mathrm{HbA}_{1 \mathrm{c}}$ at 12 months

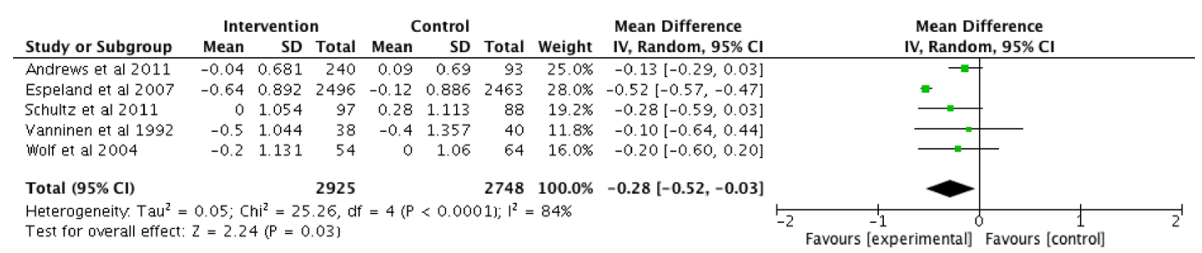

d

Difference in $\mathrm{HbA}_{1 \mathrm{c}}$ at 24 months

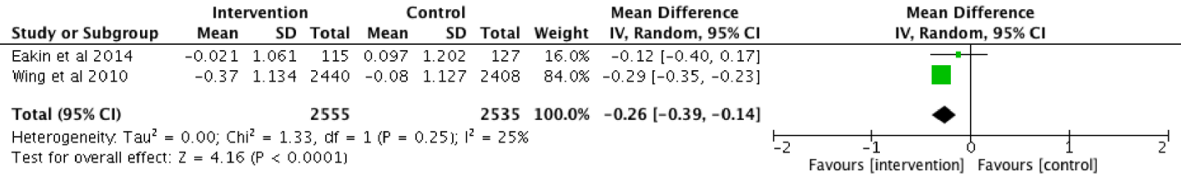

Fig. 2 Meta analyses of $\mathrm{HbA}_{1 \mathrm{c}}$ changes (\%) at $3(\mathbf{a}), 6(\mathbf{b}), 12$ (c) and 24 (d) months 


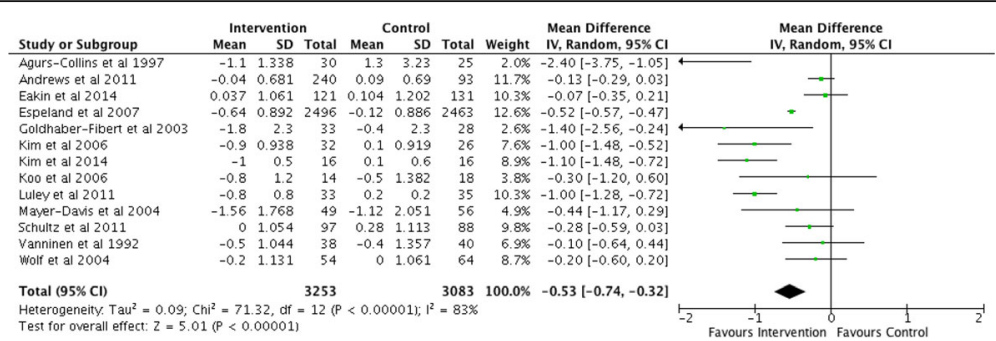

Fig. 3 Overall meta-analysis of mean difference in $\mathrm{HbA}_{1 \mathrm{c}}(\%)$ from baseline. (studies with multiple time points are represented by time point closest to the end of intervention)

(median 11). Individual BCTs and their frequency of use are reported for combined diet and/or physical activity behaviour in Table 1. Control group BCTs were coded separately, four different BCTs were identified with 'instruction on how to perform a behaviour' $(n=6)$ the most frequently occurring. BCTs coded for diet only and physical activity only are reported in Additional files 1 : 1.12 and 1.13. BCT analysis by category and BCTs not used are presented in Additional files 1: 1.14 and 1.15. $\mathrm{BCTs}$ coded and text rationale for all studies is documented in Additional file 2.

\section{Moderator analysis of BCTs}

Moderator analysis showed four BCTs for both behaviours associated with $>0.3 \%$ reduction in $\mathrm{HbA}_{1 \mathrm{c}}$. Presence of the BCTs 'instruction on how to perform a behaviour' (-0.549 \%), 'behavioural practice/rehearsal' $(-0.417 \%)$, 'action planning' (-0.385 \%) and 'demonstration of the behaviour' (-0.343), were associated with clinically significant reductions in $\mathrm{HbA}_{1 \mathrm{c}}$. Seven other BCTs were associated with reductions in $\mathrm{HbA}_{1 \mathrm{c}}$ with the $\mathrm{BCTs}$ 'graded tasks' (-0.217\%), and 'feedback on behaviour' $(-0.203 \%)$ showing the strongest association but these were not clinically or statistically significant (Table 2).

When the moderator analysis was run separately for dietary BCTs, the BCT 'demonstration of the behaviour' was associated with clinical and statistically significant reductions in $\mathrm{HbA}_{1 \mathrm{c}}$. The $\mathrm{BCTs}$ 'behavioural practice/rehearsal' and 'instruction on how to perform a behaviour', were associated with clinically significant reductions (Additional file 1: 1.16). Moderator analysis for physical activity showed three BCTs associated with clinically significant reductions in $\mathrm{HbA}_{1 \mathrm{c}}$, 'instruction on how to perform a behaviour', 'credible source' and 'behavioural practice/rehearsal' (Additional file 1: 1.17). Moderator analysis of intervention features are documented in Table 3.

\section{Discussion}

We found significant mean reductions in $\mathrm{HbA}_{1 \mathrm{c}}$ at three and six months but not at 12 or 24 months. Reductions in body weight were observed at all time points and were greatest at 12 months. Results revealed four BCTs and nine intervention features associated with clinically significant reductions in $\mathrm{HbA}_{1 \mathrm{c}}(>0.3 \%)$. These findings are exploratory but lay a foundation for future hypotheses with clinical and research implications.

\section{Combining diet and physical activity}

Overall $\mathrm{HbA}_{1 \mathrm{c}}$ results of this review highlight the value of combining diet and physical activity and the difficulty in maintaining initial reductions in $\mathrm{HbA}_{1 \mathrm{c}}$ over time. Diet and physical activity interventions produced superior results in our review $(-0.53 \%)$ and other reviews $(-0.58 \%)$ [48] compared to physical activity only, [7] dietary treatment only, [49] computer based interventions [50] and psychological interventions [51]. Reviews have shown that physical activity was associated with a reduction in $\mathrm{HbA}_{1 \mathrm{c}}$, but only when combined with diet $[48,52]$. Our observed reduction in weight $(3.73 \mathrm{~kg})$ is similar to other reviews of $3.2 \mathrm{~kg}$ [53], $3.0 \mathrm{~kg}$ [13] and 3 to $5 \mathrm{~kg}$ [52] in those at risk of type 2 diabetes but greater than reviews of diet only: low-carbohydrate $(0.69 \mathrm{~kg})$ or Mediterranean diets $(1.84 \mathrm{~kg})$ [49]. A meta-analysis reported that a physical activity and behavioural intervention in addition to a diet intervention lost $3 \mathrm{~kg}$ more weight than diet only and even greater weight losses were achieved with higher intensity physical activity [34].

Most interventions in type 2 diabetes focus on multiple rather than single behaviour change [54], however changing multiple behaviours simultaneously is difficult [55]. Changing multiple behaviours simultaneously rather than changing behaviours individually has been found to be more effective in changing at least one behaviour [55]. The mechanistic basis for this is unclear. The extent to which diet and physical activity interventions interact synergistically is also unclear. It has been suggested that successful behaviour change in one behaviour can facilitate change in other behaviours and it may be more appropriate to target behavioural patterns [56]. A qualitative study suggested that physical activity plays a greater supporting role for dietary behaviour change than dietary behaviour change did for physical activity, and should be the first behaviour individuals are 
Table 2 Moderator analysis of $\mathrm{HbA}_{1 c}$ for diet AND physical activity BCTs

\begin{tabular}{|c|c|c|c|c|c|c|c|c|c|c|c|}
\hline \multirow[b]{2}{*}{ BCT No. } & \multirow[b]{2}{*}{$\mathrm{BCTS}$} & \multirow[b]{2}{*}{ k present (absent) } & \multicolumn{3}{|c|}{ Effect size $95 \% \mathrm{Cl}$} & \multicolumn{3}{|c|}{ Effect size $95 \% \mathrm{Cl}$} & \multicolumn{3}{|c|}{ Subgroup analysis } \\
\hline & & & Present & Lower limit & Upper limit & Absent & Lower limit & Upper limit & $\mathrm{Q}$ & $P$ & Difference \\
\hline 4.1 & Instruction on how to perform a behaviour & $13(0)$ & -0.549 & -0.762 & -0.337 & & & & 0 & 1 & -0.549 \\
\hline 8.1 & Behavioural practice/rehearsal & $5(8)$ & -0.833 & -1.251 & -0.415 & -0.416 & -0.733 & -0.1 & 2.423 & 0.12 & -0.417 \\
\hline 1.4 & Action planning & $12(1)$ & -0.585 & -0.811 & -0.36 & -0.2 & -0.922 & 0.522 & 0.996 & 0.318 & -0.385 \\
\hline 6.1 & Demonstration of the behaviour & $7(6)$ & -0.701 & -0.997 & -0.405 & -0.358 & -0.702 & -0.013 & 2.201 & 0.138 & -0.343 \\
\hline 8.7 & Graded tasks & $7(6)$ & -0.653 & -0.96 & -0.346 & -0.436 & -0.785 & -0.087 & 0.833 & 0.361 & -0.217 \\
\hline 2.2 & Feedback on behaviour & $7(6)$ & -0.641 & -0.939 & -0.343 & -0.438 & -0.792 & -0.084 & 0.74 & 0.39 & -0.203 \\
\hline 12.3 & Avoidance/reducing exposure to cues for the behaviour & $4(9)$ & -0.694 & -1.209 & -0.179 & -0.53 & -0.848 & -0.212 & 0.283 & 0.595 & -0.164 \\
\hline 2.3 & Self-monitoring of behaviour & $9(4)$ & -0.612 & -0.894 & -0.329 & -0.453 & -0.846 & -0.06 & 0.414 & 0.52 & -0.159 \\
\hline 1.2 & Problem solving & $5(8)$ & -0.647 & -1.111 & -0.183 & -0.539 & -0.869 & -0.208 & 0.139 & 0.709 & -0.108 \\
\hline 1.5 & Review behaviour goal(s) & $3(10)$ & -0.618 & -1.09 & -0.145 & -0.551 & -0.859 & -0.242 & 0.054 & 0.816 & -0.067 \\
\hline 12.5 & Adding objects to the environment & $7(6)$ & -0.565 & -0.854 & -0.276 & -0.542 & -0.9 & -0.183 & 0.01 & 0.921 & -0.023 \\
\hline 1.7 & Review outcome goal(s) & $3(10)$ & -0.536 & -0.943 & -0.129 & -0.573 & -0.861 & -0.284 & 0.021 & 0.884 & 0.037 \\
\hline 2.7 & Feedback on outcome(s) of behaviour & $3(10)$ & -0.53 & -0.977 & -0.082 & -0.585 & -0.888 & -0.282 & 0.04 & 0.841 & 0.055 \\
\hline 1.1 & Goal setting (behaviour) & $11(2)$ & -0.53 & -0.772 & -0.289 & -0.654 & -1.17 & -0.138 & 0.182 & 0.67 & 0.124 \\
\hline 12.1 & Restructuring the physical environment & $3(10)$ & -0.47 & -1.022 & 0.081 & -0.61 & -0.923 & -0.297 & 0.186 & 0.666 & 0.14 \\
\hline 2.5 & Monitoring outcome(s) of behaviour by others without feedback & $5(8)$ & -0.44 & -0.818 & -0.061 & -0.639 & -0.942 & -0.336 & 0.647 & 0.421 & 0.199 \\
\hline 1.3 & Goal setting (outcome) & $10(3)$ & -0.472 & -0.697 & -0.247 & -0.908 & -1.408 & -0.409 & 2.437 & 0.118 & 0.436 \\
\hline 2.4 & Self-monitoring of outcome(s) of behaviour & $3(10)$ & -0.251 & -0.633 & 0.131 & -0.714 & -0.99 & -0.438 & 3.71 & 0.054 & 0.463 \\
\hline 3.1 & Social support (unspecified) & $10(3)$ & -0.45 & -0.678 & -0.221 & -0.92 & -1.372 & -0.468 & 3.309 & 0.069 & 0.47 \\
\hline 9.1 & Credible source & $12(1)$ & -0.491 & -0.709 & -0.274 & -1 & -1.627 & -0.373 & 2.254 & 0.133 & 0.509 \\
\hline
\end{tabular}


Table 3 Moderator analysis of intervention features for diet and physical activity

\begin{tabular}{|c|c|c|c|c|c|c|c|c|c|c|}
\hline \multirow[b]{2}{*}{ Intervention Features } & \multirow[b]{2}{*}{ k present (absent) } & \multicolumn{3}{|c|}{ Effect size $95 \%$ Cl } & \multicolumn{3}{|c|}{ Effect size $95 \% \mathrm{Cl}$} & \multicolumn{3}{|c|}{$\underline{\text { Subgroup analysis }}$} \\
\hline & & Present & Lower limit & Upper limit & Absent & Lower limit & Upper limit & Q & $\mathrm{P}$ & Difference \\
\hline \multicolumn{11}{|l|}{ Mode } \\
\hline Supervised physical activity component & $5(8)$ & -0.94 & -1.323 & -0.558 & -0.368 & -0.631 & -0.106 & 5.852 & 0.016 & -0.572 \\
\hline Individual face to face & $6(7)$ & -0.545 & -0.885 & -0.204 & -0.576 & -0.905 & -0.247 & 0.017 & 0.897 & 0.031 \\
\hline Group sessions only & $5(8)$ & -0.856 & -1.218 & -0.495 & -0.408 & -0.643 & -0.172 & 4.16 & 0.041 & -0.448 \\
\hline Combination of group and individual sessions & $4(9)$ & -0.545 & -1.013 & -0.077 & -0.588 & -0.914 & -0.263 & 0.022 & 0.881 & 0.043 \\
\hline Individual contact only & $4(9)$ & -0.349 & -0.712 & 0.015 & -0.661 & -0.93 & -0.393 & 1.841 & 0.175 & 0.312 \\
\hline \multicolumn{11}{|l|}{ Frequency } \\
\hline Frequency of total contacts $(\text { median }=1.73)^{a}$ & $7(6)$ & -0.828 & -1.083 & -0.574 & -0.17 & -0.456 & 0.116 & 11.358 & 0.001 & -0.658 \\
\hline Frequency of total contacts (mean 2.61) ${ }^{a}$ & $10(3)$ & -0.705 & -0.932 & -0.479 & -0.101 & -0.469 & 0.268 & 7.501 & 0.006 & -0.604 \\
\hline Frequency of face to face contacts (median 1.96) ${ }^{\mathrm{a}}$ & $6(7)$ & -0.934 & -1.316 & -0.552 & -0.313 & -0.627 & 0.001 & 6.061 & 0.014 & -0.621 \\
\hline Frequency of face to face contacts (mean 3.13) ${ }^{\mathrm{a}}$ & $8(5)$ & -0.764 & -1.089 & -0.438 & -0.322 & -0.678 & 0.034 & 3.224 & 0.073 & -0.442 \\
\hline \multicolumn{11}{|l|}{ Provider } \\
\hline Contact with exercise physiologist, trainer & $6(7)$ & -0.762 & -1.124 & -0.401 & -0.398 & -0.73 & -0.066 & 2.12 & 0.145 & -0.364 \\
\hline Combination of dietitian and exercise physiologist & $4(9)$ & -0.778 & -1.222 & -0.334 & -0.466 & -0.778 & -0.155 & 1.272 & 0.259 & -0.312 \\
\hline Contact with dietitian/ nutritionist & $10(3)$ & -0.488 & -0.677 & -0.219 & -0.886 & -1.316 & -0.455 & 3.093 & 0.079 & 0.398 \\
\hline $\begin{array}{l}\text { Interventionist other than dietitian, exercise } \\
\text { physiologist, i.e. nurse, doctor }\end{array}$ & $4(9)$ & -0.477 & -0.848 & -0.046 & -0.628 & -0.928 & -0.327 & 0.5 & 0.48 & 0.151 \\
\hline \multicolumn{11}{|l|}{ Intensity } \\
\hline Intensity: number of face to face contacts (median (16) ${ }^{a}$ & $7(6)$ & -0.804 & -1.144 & -0.465 & -0.32 & -0.66 & 0.02 & 3.9 & 0.048 & -0.484 \\
\hline Intensity: number of face to face contacts (mean (20.2) ${ }^{\mathrm{a}}$ & $4(9)$ & -0.784 & -1.261 & -0.307 & -0.481 & -0.79 & -0.172 & 1.092 & 0.296 & -0.303 \\
\hline $\begin{array}{l}\text { Intensity: number of total contacts with intervention } \\
\text { personnel (median }(25.5)^{\mathrm{a}}\end{array}$ & $7(6)$ & -0.609 & -0.905 & -0.314 & -0.479 & -0.842 & -0.117 & 0.297 & 0.585 & -0.13 \\
\hline $\begin{array}{l}\text { Intensity: number of total contacts with intervention } \\
\text { personnel (mean (29.2) }\end{array}$ & $5(8)$ & -0.75 & -1.075 & -0.426 & -0.39 & -0.684 & -0.097 & 2.599 & 0.107 & -0.36 \\
\hline \multicolumn{11}{|l|}{ Other } \\
\hline Use of theory/model to inform intervention & $3(10)$ & -0.483 & -0.994 & 0.029 & -0.567 & -0.807 & -0.327 & 0.086 & 0.769 & 0.084 \\
\hline Baseline $\mathrm{HbA} 1 \mathrm{c}$ levels $>8 \%^{\mathrm{b}}$ & $5(8)$ & -0.943 & -1.397 & -0.49 & -0.441 & -0.677 & -0.205 & 3.707 & 0.054 & -0.502 \\
\hline Baseline $\mathrm{HbA} 1 \mathrm{c}$ levels $>7 \%^{\mathrm{b}}$ & $12(1)$ & -0.608 & -0.837 & -0.379 & -0.13 & -0.754 & 0.494 & 1.983 & 0.159 & -0.478 \\
\hline Number of BCT's Median (11) & $6(7)$ & -0.469 & -0.806 & -0.131 & -0.627 & -0.932 & -0.323 & 0.469 & 0.494 & 0.158 \\
\hline Number of BCT's Mean $(14.85)^{c}$ & $4(9)$ & -0.694 & -1.209 & -0.179 & -0.53 & -0.848 & -0.212 & 0.283 & 0.595 & -0.164 \\
\hline
\end{tabular}

Meta-analysis (random effects model was used to assess the data)

a Present denotes higher frequency/intensity, absent denotes lower frequency/intensity, above and below mean/median

${ }^{\mathrm{b}}$ Present denotes high baseline $\mathrm{HbA1c}$, absent denotes lower HbA1c, above and below mean/median

'Present denotes higher number of BCTs, absent denotes lower number of BCTs, above and below mean/median 
encouraged to change [57], however, a study comparing sequential versus simultaneous delivery concluded that simultaneous delivery of diet and physical activity programmes may yield the most effective outcomes [58].

\section{BCTs}

\section{Frequently used and number of BCTs}

The most frequently used BCTs in diet and physical activity interventions may not be the most effective. Eleven BCTs showed a reduction in $\mathrm{HbA}_{1 \mathrm{c}}$, however only six of these were among the ten most frequently used BCTs suggesting that only $60 \%$ of the most frequently used BCTs were effective which could have important implications for intervention study design, resource utilisation and cost effectiveness. A review of physical activity interventions showed that only $50 \%$ of the most frequently used $\mathrm{BCTs}$ were associated with reductions in $\mathrm{HbA}_{1 \mathrm{c}}$ [7]. It's possible that less frequently reported BCTs not included in the moderator analysis $(n=26)$ are associated with reductions in $\mathrm{HbA}_{1 \mathrm{c}}$. Another possible conclusion could be that certain BCTs are necessary but not sufficient elements of interventions and perhaps the presence of certain BCTs is required for the key BCTs to work as intended. Our work suggests that researchers need to conduct a detailed behavioural diagnosis prior to designing their interventions, possibly using a framework such as Michie et al.'s COM$\mathrm{B}$, to align BCTs with sources of behaviour, intervention functions and policy categories as different BCTs may be more appropriate for certain individuals, behaviours, personalities, psychological profiles or different modes of delivery.

Improvements in $\mathrm{HbA}_{1 \mathrm{c}}$ were also associated with the use of a greater number of BCTs in this review also observed in other studies using $\mathrm{HbA}_{1 \mathrm{c}}$ [7] and weight loss as outcomes $[12,13]$. However, how using a greater or lesser number of BCTs in intervention studies can affect outcomes remains unclear and requires further investigation [13]. The number of BCTs used is inextricably linked to quality of reporting and the fidelity of use of BCTs. Greater treatment fidelity and quality reporting of interventions will enhance confidence, robustness and study power of reported results [59].

\section{$\mathrm{BCT}$ s associated with reductions in $\mathrm{HbA}_{1 \mathrm{c}}$}

We identified four BCTs associated with clinically significant reductions in $\mathrm{HbA}_{1 \mathrm{c}}$ : 'instruction on how to perform a behaviour', 'behavioural practice/rehearsal' 'action planning' and 'demonstration of the behaviour'. These have all been reported previously as having a positive impact on diet and physical activity behaviour $[13,14,17]$. Usually the three BCTs: instruction on how to perform a behaviour,' 'behavioural practice/rehearsal' and 'demonstration of the behaviour' are coded together when delivered through classes such as exercise or cookery. This coding principle might explain the emergence of these three BCTs as key to changing diet and physical activity behaviour as it's possible that these three BCTs work in isolation but more likely that the presence of all three allows them to work synergistically. This also highlights that some $\mathrm{BCTs}$ lend themselves well to certain modes of delivery. Success of these three BCTs might be explained by their strong theoretical foundations [60, 61]. The Social Cognitive Theory includes 'observational learning' as one of its five basic capabilities of human functioning [61]. The 'vicarious capability' suggested in this model outlines our ability to learn through observation and modeling behaviour of others and is intertwined in these three BCTs and a review of nutrition counseling strategies suggested including skill development coaching/training and demonstration or modeling [18].

One BCT from the 'goals and planning' category, 'action planning' was associated with clinically significant reductions in $\mathrm{HbA}_{1 \mathrm{c}}$. This $\mathrm{BCT}$ has also been associated with successful behaviour change in several other studies $[7,12-15,18]$. The BCT 'action planning' facilitates behaviour change by providing a clear pathway in identifying context, frequency, duration and intensity of the required behaviour change. Constructs from this BCT highlight the importance of self-regulatory processes in behaviour change [62] and can be seen in several behaviour change theories $[63,64]$.

Two BCTs from the 'feedback and monitoring' category 'feedback on behaviour' and 'self-monitoring of behaviour' were associated with reductions in $\mathrm{HbA}_{1 \mathrm{c}}$. These $\mathrm{BCTs}$ have also been associated with successful behaviour change in other studies $[12-16,18]$ and similar constructs are described in a theoretical model [61]. BCTs in this category can help keep the behaviour change on track, allow for adjustment and self-regulation and may be more important in maintaining than initiating behaviour change as it's necessary to self-monitor behaviour to self-regulate behaviour [62]. As motivation decreases and opportunity costs increase, there is a greater need for self-regulatory effort [65]. However, according to the Control Theory [66] the self-regulation process of how we set and prioritize our goals is based on a hierarchical structure. It's also thought that the self-regulatory process or willpower to sustain behavioural change draws on a mental resource requiring energy and one which can be depleted, making subsequent tasks more difficult [67].

Several authors have highlighted the benefits of using the BCTs 'goal setting' $[7,12,18]$ 'goal review', 'social support' [12], 'prompt practice' [13], 'use of follow up prompts' $[15,18]$ and 'prompting generalisation of a target behaviour' [7] to positively affect behaviour change of diet and/or physical activity. However, these findings 
were not observed in our review, possibly due to limitations outlined in this study or limitations in reporting.

\section{BCTs not used and other factors}

Some of the best established BCTs [25, 26] for behaviour change were conspicuous in their absence from any of the RCTs in this review. These included 'behavioural contract' and 'commitment'. Behaviour change is almost impossible without a high level of commitment. Interventions could benefit from assessing levels of commitment prior to intervention. Lesser-used categories 'Reward and threat' and 'Identity' could also represent opportunities for behaviour change $[14,68]$ as identity represents one of the strongest drivers for behaviour change, and has been associated with positive changes in health outcomes, $[68,69]$ as did BCTs using automatic process such as 'habit formation' and 'habit reversal' [70].

It is also possible that some BCTs have a negative effect on behaviour. In this review presence of four BCTs 'goal setting (outcome),' 'self-monitoring of outcomes of behaviour,' 'social support' and 'credible source', were associated with clinically significant increases in $\mathrm{HbA}_{1 \mathrm{c}}$. Although the 'credible source' BCT data are heavily skewed by one study, evidence suggests that monitoring outcomes of behaviour and setting outcome-related goals may negatively affect diet and/or physical activity behaviour. This finding warrants further investigation.

Another factor not considered in this review is the study of epigenetics, the complex relationship between the environment and genes [71] and to what extent diet and physical activity behaviours may be genetically determined and influenced.

\section{Intervention features}

This review identified nine intervention features associated with clinically significant reductions in $\mathrm{HbA}_{1 \mathrm{c}}$. Interventions where the physical activity component was supervised $(n=5)$ showed one of the strongest moderating effects with both aerobic [37, 41, 43] and strength based activities [42, 72]. Interventions that use group sessions only' were associated with greater effectiveness than those with individual sessions only. However, higher frequency and intensity of individual contact was associated with greater effectiveness. Evidence suggests that females may benefit more from group sessions [73] while males may benefit more from individual sessions [74].

Our findings suggest that diet and physical activity interventions delivered by an exercise physiologist or an exercise physiologist and a dietitian through face-to-face contact may be the best way to deliver these interventions, though cost-effectiveness was not assessed. Interventions delivered by non-diet or exercise specialists (doctor, nurse) were not associated with success, which suggests that diet and/or physical activity interventions need to be delivered by experts in that area. While app delivered interventions hold promise, [75] our findings suggest that frequent personal contact and supervised physical activity may enhance effectiveness.

A gradual increase in intensity and frequency of contact could well assist in achieving maintenance of behaviour change of diet and physical activity as simple tasks in the initial stages of interventions, gradually progressing in intensity, could help improve participants' self-efficacy $[76,77]$. Three out of four interventions reporting multiple time points reported that initial reductions in $\mathrm{HbA}_{1 \mathrm{c}}$ were not maintained $[38,43,46]$. The increased effectiveness of gradually increasing interventions may also be explained by their role in tackling habituation, or boredom, or providing increased support as behaviour change becomes more challenging following the initial stages.

Our review suggests that the BCT 'graded tasks' was associated with a reduction in $\mathrm{HbA}_{1 \mathrm{c}}$, and positive health outcomes in another review [78]. The BCT 'graded tasks' can play a key role in developing habits which is among the five theoretical themes suggested for behavioral change maintenance [65] and may inform better maintenance of behaviour change in diet and physical activity interventions.

\section{Use of theory}

Only three out of 13 RCTs mentioned use of a theory or model in designing intervention [39, 43, 46]. It wasn't possible to ascertain to what degree these studies were guided by theory as fidelity to theory was not reported. One study [43] reported that the behavioural component 'was based on' the Social Action theory [79], a second study [39] reported that they used 'concepts' from this theory, while another [46] reported that methods used were 'grounded' in the Social Cognitive Theory [61]. In evaluating and developing complex interventions, a strong theoretical understanding is required to identify and strengthen the weakest links in the causal chain [80]. Interventions guided by theory or theoretical constructs may be more effective in changing a variety of health behaviours than studies not using theory [81]. However, a study of the extent and use of theory in physical activity and healthy eating interventions suggested that theories were not used extensively in the development of interventions and when theory was used the relationship between effectiveness and extent and use of theory was weak [82] which is corroborated by data from this review.

\section{Study strengths and limitations}

We used the most recent BCT taxonomy (v1) to code interventions. To maximise the quality of the research being reviewed only RCTs were included. The detailed reporting of outcomes of $\mathrm{HbA}_{1 \mathrm{c}}$ and reduction in body weight at different time points allow for investigation of effect size and trends over time. The systematic detailing of BCT coding 
procedures, results, and high inter-rater reliability allows future researchers to replicate and review methods used in detail. The overall risk of bias was low. This review is, to the best of our knowledge, the first to document key BCTs and intervention features associated with reductions in $\mathrm{HbA}_{1 \mathrm{c}}$ in diet and physical activity interventions for type 2 diabetes.

Some limitations also warrant mention. Results of this review can be considered exploratory as no causality of $\mathrm{BCTs}$ /intervention features associated with clinically significant reductions in $\mathrm{HbA}_{1 \mathrm{c}}$ can be concluded, and the presence of a BCT can only infer association. The strict inclusion criteria limited the review to 13 studies, and large heterogeneity reduced study power and robustness of results in elucidating $\mathrm{HbA}_{1 \mathrm{c}}$ effect sizes. Coding of the BCTs depended on the reporting quality, quantity, and accuracy within the RCTs themselves, and these varied considerably. For instance, regarding the Look Ahead Trial $[38,83]$, when the RCT results paper was coded, 11 BCTs were identified; when the methodology paper was coded, 16 BCTs were identified [84]; however, when all 88 supporting documents (https://www.lookaheadtrial.org/) were coded, 42 BCTs were identified. A study of smoking interventions showed similar results [85]. The majority of reviewed studies did not reference an associated methodology paper, rendering it possible that other BCTs were used but not coded. Fidelity was poorly reported, therefore, it was not possible to determine if BCTs were delivered, received or enacted as intended. It was not possible to code the dose, frequency or sequence of use of BCTs or to ascertain which BCTs were associated with initiation or maintenance of behaviour change. Comparisons drawn between this review and previous studies should take into account the different BCT Taxonomies used [25, 86-88]. Variation between studies in subject's duration of diabetes and baseline $\mathrm{HbA}_{1 \mathrm{c}}$ may also have increased heterogeneity. The majority of the included studies did not report behaviour change for diet or physical activity as an outcome measure.

\section{Implications and future directions}

From a research perspective we recommend that a formal assessment of the effectiveness of individual and clustered BCTs in the initiation and maintenance of behaviour change should be a scientific priority. The hierarchical ranking of BCTs and the synergistic effect of certain $\mathrm{BCTs}$ requires further investigation. We recommend firstly that clearly defined and reported behavioural outcome measures are incorporated into diet and or physical activity interventions and studies follow TIdieR guidelines [89]. Secondly, more transparent and comprehensive descriptions of BCTs used, fidelity to intervention protocol and clarity regarding the theoretical constructs and models used in published studies is required.
From a practice perspective, findings of this manuscript suggest support for implementing a graded approach to gradually increasing frequency and intensity of intervention content, structuring interventions so that the key components are delivered by credible experts (i.e. exercise physiologists and dietitians) and alignment of behaviour change techniques to target behaviours following a comprehensive behavioural diagnosis.

\section{Conclusion}

Our findings show that combined diet and physical activity interventions achieved clinically meaningful reductions in $\mathrm{HbA}_{1 \mathrm{c}}$ at 3 and 6 months, but these were not sustained at 12 and 24 months. We identified four $\mathrm{BCTs}$ and nine intervention features associated with reductions in $\mathrm{HbA}_{1 \mathrm{c}}$. These exploratory findings may guide future research into BCTs such as 'instruction on how to perform a behaviour,' 'behavioural practice/rehearsal', 'action planning,' and 'demonstration of the behaviour' which seemed to be associated with better outcomes in type 2 diabetic adults in addition to the intervention features identified.

\section{Additional files}

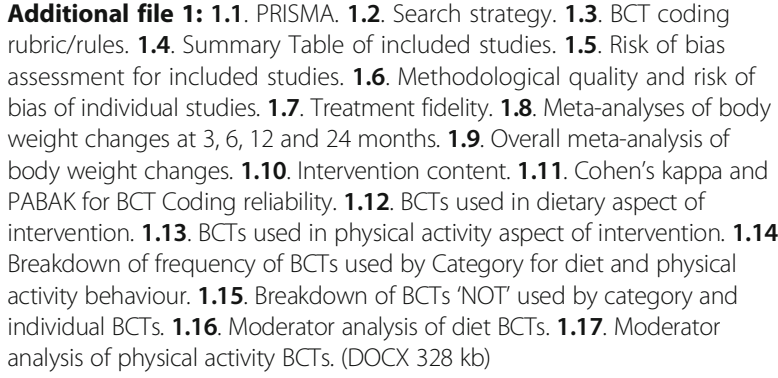

Additional file 1: 1.1. PRISMA. 1.2. Search strategy. 1.3. BCT coding rubric/rules. 1.4. Summary Table of included studies. 1.5. Risk of bias assessment for included studies. 1.6. Methodological quality and risk of bias of individual studies. 1.7. Treatment fidelity. 1.8. Meta-analyses of body weight changes at 3, 6, 12 and 24 months. 1.9. Overall meta-analysis of body weight changes. 1.10. Intervention content. 1.11. Cohen's kappa and PABAK for BCT Coding reliability. 1.12. BCTs used in dietary aspect of intervention. 1.13. BCTs used in physical activity aspect of intervention. 1.14 Breakdown of frequency of BCTs used by Category for diet and physical activity behaviour. 1.15. Breakdown of BCTs 'NOT' used by category and individual BCTs. 1.16. Moderator analysis of diet BCTs. 1.17. Moderator analysis of physical activity BCTs. (DOCX $328 \mathrm{~kb}$ )

Additional file 2: Excel file documenting text for each BCT for all included studies. (XLSX $113 \mathrm{~kb}$ )

\section{Acknowledgments \\ We would like to thank Laraib Sherish and Raymond Khanano for their assistance with the search process, Desi McEwan for assistance with the moderator analysis; Kylie Mallory for assistance with formatting tables. We wish to thank the Irish Research Council (IRC) for funding this project.}

Funding

PhD scholarship funding was provided to KC by the Irish Research Council (IRC).

Availability of data and material

All data and material is available.

Authors' contributions

$K C, L Q, G O L, F F$ and KMG formulated the research question, defined the search terms. KC carried out the electronic searches. KC and KMG carried out the search process and the methodological assessment, KC and LQ carried out the BCT coding, $\mathrm{HG}$ guided the BCT coding process and acted as a master coder. KC carried out the moderator analysis and the meta-analysis. All authors were involved in writing and reviewing the final manuscript. All authors read and approved the final manuscript. 


\section{Competing interests}

The authors declare that they have no competing interests.

\section{Consent for publication}

All authors give their consent for the content of this work to be published.

\section{Ethics approval and consent to participate}

Not Applicable.

\begin{abstract}
Author details
'Physiology, School of Medicine, NUI Galway, University Road, Galway, Ireland. ${ }^{2}$ Electrical \& Electronic Engineering, School of Engineering \& Informatics, NUI Galway, University Road, Galway, Ireland. ${ }^{3}$ National Centre for Biomedical Engineering Science, NUI Galway, University Road, Galway, Ireland. ${ }^{4}$ Bariatric Medicine Service, Galway Diabetes Research Centre, HRB Clinical Research Facility, Galway, Ireland. ${ }^{5}$ School of Health and Exercise Sciences, Faculty of Health and Social Development, The University of British Columbia, ART 129- 1147, Research Road, Kelowna, BC V1V 1 V7, Canada. ${ }^{6}$ School of Health and Exercise Sciences, Faculty of Health and Social Development, The University of British Columbia, ART 129-1147 Research Road, Kelowna, BC V1V 1 V7, Canada.
\end{abstract}

Received: 18 July 2016 Accepted: 17 October 2016

Published online: 08 February 2017

\section{References}

1. Federation ID: International Diabetes Federation, IDF Diabetes Atlas, 7th edn. Brussels, Belgium; 2015. http://www.diabetesatlas.org.

2. Wild S, Roglic G, Green A, Sicree R, King H. Global prevalence of diabetes: estimates for the year 2000 and projections for 2030. Diabetes Care. 2004; 27(5):1047-53.

3. Lozano R, Naghavi M, Foreman K, Lim S, Shibuya K, Aboyans V, Abraham J, Adair T, Aggarwal R, Ahn SY, et al. Global and regional mortality from 235 causes of death for 20 age groups in 1990 and 2010: A systematic analysis for the global burden of disease study 2010. Lancet. 2012;380(9859):2095-128.

4. Position Statement. Standards of medical care in diabetes-2014. Diabetes Care. 2014;37(SUPPL.1):S14-S80.

5. Keogh KM, Smith SM, White P, McGilloway S, Kelly A, Gibney J, O'Dowd T. Psychological family intervention for poorly controlled type 2 diabetes. Am J Manag Care. 2011;17:105-13.

6. Dasgupta K, Hajna S, Joseph L, Da Costa D, Christopoulos S, Gougeon R. Effects of meal preparation training on body weight, glycemia, and blood pressure: results of a phase 2 trial in type 2 diabetes. Int J Behav Nutr phys Act. 2012;9:125.

7. Avery L, Flynn D, Van Wersch A, Sniehotta FF, Trenell MI. Changing physical activity behavior in type 2 diabetes: A systematic review and meta-analysis of behavioral interventions. Diabetes Care. 2012;35(12):2681-9.

8. Tricco AC, Ivers NM, Grimshaw JM, Moher D, Turner L, Galipeau J, Halperin I, Vachon B, Ramsay T, Manns B, et al. Effectiveness of quality improvement strategies on the management of diabetes: A systematic review and meta-analysis. Lancet. 2012;379(9833):2252-61.

9. Després JP, Poirier P. Diabetes: Looking back at Look AHEAD - Giving lifestyle a chance. Nat Rev Cardiol. 2013;10(4):184-6.

10. Hu FB. Globalization of diabetes: The role of diet, lifestyle, and genes. Diabetes Care. 2011;34(6):1249-57.

11. Wing RR, Goldstein MG, Acton KJ, Birch LL, Jakicic JM, Sallis Jr JF, SmithWest D, Jeffery RW, Surwit RS. Behavioral science research in diabetes: Lifestyle changes related to obesity, eating behavior, and physical activity. Diabetes Care. 2001;24(1):117-23.

12. Hankonen N, Sutton S, Prevost AT, Simmons RK, Griffin SJ, Kinmonth AL, Hardeman W: Which Behavior Change Techniques are Associated with Changes in Physical Activity, Diet and Body Mass Index in People with Recently Diagnosed Diabetes? Ann Behav Med. 2014;49(1):7-17.

13. Dombrowski SU, Sniehotta FF, Avenell A, Johnston M, MacLennan G, Araújo-Soares V. Identifying active ingredients in complex behavioural interventions for obese adults with obesity-related co-morbidities or additional risk factors for co-morbidities: a systematic review. Health Psychol Rev. 2012;6(1):7-32.

14. French DP, Olander EK, Chisholm A, Mc Sharry J: Which Behaviour Change Techniques Are Most Effective at Increasing Older Adults' Self-Efficacy and
Physical Activity Behaviour? A Systematic Review. Ann Behav Med. 2014; 48(2):225-134.

15. Lara J, Hobbs N, Moynihan PJ, Meyer TD, Adamson AJ, Errington L, Rochester L, Sniehotta FF, White M, Mathers JC: Effectiveness of dietary interventions among adults of retirement age: A systematic review and meta-analysis of randomized controlled trials. BMC Med 2014, 12(1). doi: 10.1186/1741-7015-12-60.

16. Michie S, Abraham C, Whittington C, McAteer J, Gupta S. Effective Techniques in Healthy Eating and Physical Activity Interventions: A MetaRegression. Health Psychol. 2009;28(6):690-701.

17. Hartmann-Boyce J, Johns DJ, Jebb SA, Aveyard P, Ogden J, Onakpoya I, Summerbell C, Phillips D. Effect of behavioural techniques and delivery mode on effectiveness of weight management: Systematic review, metaanalysis and meta-regression. Obes Rev. 2014;15(7):598-609.

18. Spahn JM, Reeves RS, Keim KS, Laquatra I, Kellogg M, Jortberg B, Clark NA. State of the evidence regarding behavior change theories and strategies in nutrition counseling to facilitate health and food behavior change. J Am Diet Assoc. 2010;110(6):879-91.

19. Mokdad AH, Marks JS, Stroup DF, Gerberding JL. Actual Causes of Death in the United States, 2000. J Am Med Assoc. 2004;291(10):1238-45.

20. Michie S, Johnston M. Theories and techniques of behaviour change: Developing a cumulative science of behaviour change. Health Psychol Rev. 2012;6(1):1-6.

21. Dombrowski SU, Knittle K, Avenell A, Araújo-Soares V, Sniehotta FF. Long term maintenance of weight loss with non-surgical interventions in obese adults: Systematic review and meta-analyses of randomised controlled trials. BMJ. 2014;348:g2646.

22. Moher D, Liberati A, Tetzlaff J, Altman DG, Altman D, Antes G, Atkins $D$, Barbour V, Barrowman N, Berlin JA, et al. Preferred reporting items for systematic reviews and meta-analyses: The PRISMA statement. PLoS Med. 2009;6(7):e1000097.

23. Higgins JPT, Altman DG, Gøtzsche PC, Jüni P, Moher D, Oxman AD, Savović J, Schulz KF, Weeks L, Sterne JAC: The Cochrane Collaboration's tool for assessing risk of bias in randomised trials. BMJ 2011, 343(7829). doi: 10.1136/bmj.d5928.

24. Bellg AJ, Resnick B, Minicucci DS, Ogedegbe G, Ernst D, Borrelli B, Hecht J, Ory M, Orwig D, Czajkowski S. Enhancing treatment fidelity in health behavior change studies: Best practices and recommendations from the $\mathrm{NIH}$ Behavior Change Consortium. Health Psychol. 2004;23(5):443-51.

25. Michie S, Richardson M, Johnston M, Abraham C, Francis J, Hardeman W, Eccles MP, Cane J, Wood CE. The behavior change technique taxonomy (v1) of 93 hierarchically clustered techniques: Building an international consensus for the reporting of behavior change interventions. Ann Behav Med. 2013;46(1):81-95.

26. BCTTv1 Online Training. [http://www.ucl.ac.uk/health-psychology/ bcttaxonomy/Online_training].

27. Davidson KW, Goldstein M, Kaplan RM, Kaufmann PG, Knatterud GL, Orleans CT, Spring B, Trudeaum KJ, Whitlock EP. Evidence-Based Behavioral Medicine: What Is It and How Do We Achieve It? Ann Behav Med. 2003; 26(3):161-71.

28. Michie S, Prestwich A. Are interventions theory-based? Development of a theory coding scheme. Health Psychol. 2010;29(1):1-8.

29. Riddle MC, Ambrosius WT, Brillon DJ, Buse JB, Byington RP, Cohen RM, Goff Jr DC, Malozowski S, Margolis KL, Probstfield JL, et al. Epidemiologic relationships between $\mathrm{A} 1 \mathrm{C}$ and all-cause mortality during a median 3.4-year follow-up of glycemic treatment in the ACCORD trial. Diabetes Care. 2010;33(5):983-90.

30. Higgins J.P.T. DJJ: Cochrane Handbook for Systematic Reviews of Interventions Version 5.1.0 (updated March 2011). Chapter 7: Selecting studies and collecting data. The Cochrane Collaboration, 2011. Available from http://handbook.cochrane.org/. 2011, Chapter 7: Selecting studies and collecting data.

31. Hozo SP, Djulbegovic B, Hozo I. Estimating the mean and variance from the median, range, and the size of a sample. BMC Med Res Methodol. 2005;5:13.

32. Follmann $D$, Elliott $P$, Suh I, Cutler J. Variance imputation for overviews of clinical trials with continuous response. J Clin Epidemiol. 1992;45(7):769-73.

33. Richardson CR, Newton TL, Abraham JJ, Sen A, Jimbo M, Swartz AM. A meta-analysis of pedometer-based walking interventions and weight loss. Ann Fam Med. 2008;6(1):69-77.

34. Norris SL, Zhang X, Avenell A, Gregg E, Bowman B, Serdula M, Brown TJ, Schmid CH, Lau J. Long-term effectiveness of lifestyle and behavioral weight loss interventions in adults with type 2 diabetes: A meta-analysis. Am J Med. 2004;117(10):762-74. 
35. Peterson MD, Rhea MR, Sen A, Gordon PM. Resistance exercise for muscular strength in older adults: A meta-analysis. Ageing Res Rev. 2010;9(3):226-37.

36. Vanninen E, Uusitupa M, Siitonen O, Laitinen J, Lansimies E. Habitual physical activity, aerobic capacity and metabolic control in patients with newly-diagnosed type 2 (non-insulin-dependent) diabetes mellitus: effect of 1-year diet and exercise intervention. Diabetologia. 1992;35(4):340-6.

37. Goldhaber-Fiebert JD, Goldhaber-Fiebert SN, Tristan ML, Nathan DM. Randomized controlled community-based nutrition and exercise intervention improves glycemia and cardiovascular risk factors in type 2 diabetic patients in rural Costa Rica. Diabetes Care. 2003;26(1):24-9.

38. Espeland M, Pi-Sunyer X, Blackburn G, Brancati FL, Bray GA, Bright R, Clark $J M$, Curtis JM, Foreyt JP, Graves K, et al. Reduction in weight and cardiovascular disease risk factors in individuals with type 2 diabetes oneyear results of the Look AHEAD trial. Diabetes Care. 2007;30(6):1374-83.

39. Mayer-Davis EJ, D'Antonio AM, Smith SM, Kirkner G, Martin SL, Parra-Medina D, Schultz R. Pounds off with empowerment (POWER): A clinical trial of weight management strategies for black and white adults with diabetes who live in medically underserved rural communities. Am J Public Health. 2004;94(10):1736-42

40. Luley C, Blaik A, Reschke K, Klose S, Westphal S. Weight loss in obese patients with type 2 diabetes: Effects of telemonitoring plus a diet combination - The Active Body Control (ABC) Program. Diabetes Res Clin Pract. 2011;91(3):286-92.

41. Kim SH, Lee SJ, Kang ES, Kang S, Hur KY, Lee HJ, Ahn CW, Cha BS, Yoo JS, Lee HC. Effects of lifestyle modification on metabolic parameters and carotid intima-media thickness in patients with type 2 diabetes mellitus. Metab Clin Exp. 2006;55:1053-9.

42. Schultz MG, Hordern MD, Leano R, Coombes JS, Marwick TH, Sharman JE. Lifestyle change diminishes a hypertensive response to exercise in type 2 diabetes. Med Sci Sports Exerc. 2011;43(5):764-9.

43. Agurs-Collins TD, Kumanyika SK, Ten Have TR, Adams-Campbell LL. A randomized controlled trial of weight reduction and exercise for diabetes management in older African-American subjects. Diabetes Care. 1997;20(10):1503-11.

44. Koo BK, Han KA, Ahn HJ, Jung JY, Kim HC, Min KW. The effects of total energy expenditure from all levels of physical activity vs. physical activity energy expenditure from moderate-to-vigorous activity on visceral fat and insulin sensitivity in obese Type 2 diabetic women. Diabet Med. 2010;27(9):1088-92.

45. Andrews R, Cooper AR, Montgomery AA, Norcross AJ, Peters TJ, Sharp DJ, Jackson N, Fitzsimons K, Bright J, Coulman K, et al. Diet or diet plus physical activity versus usual care in patients with newly diagnosed type 2 diabetes: The Early ACTID randomised controlled trial. Lancet. 2011;378(9786):129-39.

46. Eakin EG, Winkler EA, Dunstan DW, Healy GN, Owen N, Marshall AM, Graves N, Reeves MM. Living well with diabetes: 24-month outcomes from a randomized trial of telephone-delivered weight loss and physical activity intervention to improve glycemic control. Diabetes Care. 2014;37(8):2177-85.

47. Wolf AM, Conaway MR, Crowther JQ, Hazen KY, Nadler JL, Oneida B, Bovbjerg VE. Translating lifestyle intervention to practice in obese patients with type 2 diabetes: Improving Control with Activity and Nutrition (ICAN) study. Diabetes Care. 2004;27(7):1570-6

48. Umpierre D, Ribeiro PA, Kramer CK, Leitao CB, Zucatti AT, Azevedo MJ, Gross $J$, Ribeiro JP, Schaan BD. Physical activity advice only or structured exercise training and association with $\mathrm{HbA} 1 \mathrm{C}$ levels in type 2 diabetes: a systematic review and meta-analysis. JAMA. 2011;305(17):1790-9.

49. Ajala O, English P, Pinkney J. Systematic review and meta-analysis of different dietary approaches to the management of type 2 diabetes1-3. Am J Clin Nutr. 2013;97(3):505-16.

50. Pal K, Eastwood SV, Michie S, Farmer AJ, Barnard ML, Peacock R, Wood B, Inniss JD, Murray E: Computer-based diabetes self-management interventions for adults with type 2 diabetes mellitus. Cochrane Database Syst Rev 2013, 3. doi: 10.1002/14651858.CD008776.pub2.

51. Ismail K, Winkley K, Rabe-Hesketh S. Systematic review and meta-analysis of randomised controlled trials of psychological interventions to improve glycaemic control in patients with type 2 diabetes. Lancet. 2004;363(9421):1589-97.

52. Greaves CJ, Sheppard KE, Abraham C, Hardeman W, Roden M, Evans PH Schwarz P. Systematic review of reviews of intervention components associated with increased effectiveness in dietary and physical activity interventions. BMC Public Health. 2011;11:119.

53. Franz MJ, Boucher JL, Rutten-Ramos S, VanWormer JJ. Lifestyle weight-loss intervention outcomes in overweight and obese adults with type2Diabetes: A systematic review and meta-analysis of randomized clinical trials. J Acad Nutr Diet. 2015;115(9):1447-63.
54. Presseau J, Ivers NM, Newham JJ, Knittle K, Danko KJ, Grimshaw JM: Using a behaviour change techniques taxonomy to identify active ingredients within trials of implementation interventions for diabetes care. Implement Sci 2015, 10(1). doi: 10.1186/s13012-015-0248-7.

55. Hyman DJ, Pavlik VN, Taylor WC, Goodrick GK, Moye L. Simultaneous vs sequential counseling for multiple behavior change. Arch Intern Med. 2007;167(11):1152-8

56. Lippke S, Nigg CR, Maddock JE. Health-promoting and health-risk behaviors: Theory-driven analyses of multiple health behavior change in three international samples. Int J Behav Med. 2012;19(1):1-13.

57. Malpass A, Andrews R, Turner KM. Patients with Type 2 Diabetes experiences of making multiple lifestyle changes: A qualitative study. Patient Educ Couns. 2009;74(2):258-63.

58. King AC, Castro CM, Buman MP, Hekler EB, Urizar Jr GG, Ahn DK. Behavioral impacts of sequentially versus simultaneously delivered dietary plus physical activity interventions: The CALM Trial. Ann Behav Med. 2013;46(2):157-68.

59. Borrelli B: The assessment, monitoring, and enhancement of treatment fidelity in public health clinical trials. J Public Health Dent 2011, 71(SUPPL. 1):S52-S63

60. Bandura A. Self-efficacy: Toward a unifying theory of behavioral change. Psychol Rev. 1977;84(2):191-215.

61. Bandura A. Social Foundations of Thought and Action: A Social Cognitive Theory. New Jersey: Prentice-Hall; 1986.

62. Vohs KD, Baumeister RF: Handbook of self-regulation: Research, theory, and applications. New York: Guildford Press; 2011.

63. Rosenstock IM, Strecher VJ, Becker MH. Social learning theory and the Health Belief Model. Health Educ Q. 1988;15(2):175-83.

64. Schwarzer R, Luszczynska A. How to overcome health-compromising behaviors: The health action process approach. Eur Psychol. 2008;13(2):141-51.

65. Kwasnicka D, Dombrowski SU, White M, Sniehotta F: Theoretical explanations for maintenance of behaviour change: a systematic review of behaviour theories. Health Psychol Rev 2016:1-20. doi: 10.1080/17437199. 2016.1151372.

66. Carver CS, Scheier MF. Control theory: A useful conceptual framework for personality-social, clinical, and health psychology. Psychol Bull. 1982;92(1):111-35.

67. Hagger MS, Leaver E, Esser K, Leung CM, Te Pas N, Keatley DA, Chan DKC, Chatzisarantis NLD. Cue-induced smoking urges deplete cigarette smokers' self-control resources. Ann Behav Med. 2013;46(3):394-400.

68. West R, Walia A, Hyder N, Shahab L, Michie S. Behavior change techniques used by the English Stop Smoking Services and their associations with short-term quit outcomes. Nicotine Tob Res. 2010;12(7):742-7.

69. Gray CM, Hunt K, Mutrie N, Anderson AS, Leishman J, Dalgarno L, Wyke S: Football Fans in Training: The development and optimization of an intervention delivered through professional sports clubs to help men lose weight, become more active and adopt healthier eating habits. BMC Public Health 2013, 13(1). doi: 10.1186/1471-2458-13-232.

70. Carels RA, Burmeister JM, Koball AM, Oehlhof MW, Hinman N, Leroy M, Bannon E, Ashrafioun L, Storfer-Isser A, Darby LA, et al. A randomized trial comparing two approaches to weight loss: Differences in weight loss maintenance. J Health Psychol. 2014;19(2):296-311.

71. Ling C, Groop L. Epigenetics: A molecular link between environmental factors and type 2 diabetes. Diabetes. 2009;58(12):2718-25.

72. Kim SH, Lee SH, Ahn KY, Lee DH, Suh YJ, Cho SG, Choi YJ, Lee DH, Lee SY, Hong SB, et al. Effect of lifestyle modification on serum chemerin concentration and its association with insulin sensitivity in overweight and obese adults with type 2 diabetes. Clin Endocrinol. 2014;80(6):825-33.

73. Paul-Ebhohimhen $V$, Avenell A. A systematic review of the effectiveness of group versus individual treatments for adult obesity. Obes Facts. 2009;2(1):17-24.

74. Hakala P, Karvetti RL, Ronnemaa T. Group vs individual weight reduction programmes in the treatment of severe obesity - a five year follow-up study. Int J Obes. 1993;17(2):97-102.

75. Carter MC, Burley VJ, Nykjaer C, Cade JE. Adherence to a smartphone application for weight loss compared to website and paper diary: Pilot randomized controlled trial. J Med Internet Res. 2013;15(4):e32.

76. Bauman AE, Reis RS, Sallis JF, Wells JC, Loos RJF, Martin BW. Correlates of physical activity: Why are some people physically active and others not? Lancet. 2012;380(9838):258-71.

77. van Stralen MM, de Vries H, Mudde AN, Bolman C, Lechner L. Determinants of initiation and maintenance of physical activity among older adults: A literature review. Health Psychol Rev. 2009;3(2):147-207.

78. Hynynen ST, van Stralen MM, Sniehotta FF, Araújo-Soares V, Hardeman W, Chinapaw MJM, Vasankari T, Hankonen N. A systematic review of school- 
based interventions targeting physical activity and sedentary behaviour among older adolescents. Int Rev Sport Exerc Psychol. 2016;9(1):22-44.

79. Ewart CK. Social action theory for a public health psychology. Am Psychol. 1991;46(9):931-46.

80. Craig P, Dieppe P, Macintyre S, Mitchie S, Nazareth I, Petticrew M. Developing and evaluating complex interventions: The new Medical Research Council guidance. BMJ. 2008;337(7676):979-83.

81. Glanz K, Bishop DB. The role of behavioral science theory in development and implementation of public health interventions. Annu Rev Public Health. 2010;31:399-418.

82. Prestwich A, Sniehotta FF, Whittington C, Dombrowski SU, Rogers L, Michie S. Does theory influence the effectiveness of health behavior interventions? Meta-analysis. Health Psychol. 2014;33(5):465-74

83. Wing RR, Bahnson JL, Bray GA, Clark JM, Coday M, Egan C, Espeland MA, Foreyt JP, Gregg EW, Goldman V, et al. Long-term effects of a lifestyle intervention on weight and cardiovascular risk factors in individuals with type 2 diabetes mellitus: Four-year results of the look AHEAD trial. Arch Intern Med. 2010;170(17):1566-75.

84. Wadden TA. The look AHEAD study: A description of the lifestyle intervention and the evidence supporting it. Obesity. 2006;14(5):737-52.

85. Lorencatto F, West R, Stavri Z, Michie S. How well is intervention content described in published reports of smoking cessation interventions? Nicotine Tob Res. 2013;15(7):1273-82.

86. Michie S, Ashford S, Sniehotta FF, Dombrowski SU, Bishop A, French DP. A refined taxonomy of behaviour change techniques to help people change their physical activity and healthy eating behaviours: The CALO-RE taxonomy. Psychol Health. 2011;26(11):1479-98.

87. Abraham C, Michie S. A taxonomy of behavior change techniques used in interventions. Health Psychol. 2008;27(3):379-87.

88. Michie S, Hyder N, Walia A, West R. Development of a taxonomy of behaviour change techniques used in individual behavioural support for smoking cessation. Addict Behav. 2011;36(4):315-9.

89. Hoffmann TC, Glasziou PP, Boutron I, Milne R, Perera R, Moher D, Altman DG, Barbour V, Macdonald H, Johnston M, et al. Better reporting of interventions: Template for intervention description and replication (TIDieR) checklist and guide. BMJ. 2014;348.

\section{Submit your next manuscript to BioMed Central and we will help you at every step:}

- We accept pre-submission inquiries

- Our selector tool helps you to find the most relevant journal

- We provide round the clock customer support

- Convenient online submission

- Thorough peer review

- Inclusion in PubMed and all major indexing services

- Maximum visibility for your research

Submit your manuscript at www.biomedcentral.com/submit
Biomed Central 